\title{
OA TEC-Website difusor da Ética em Computação
}

\author{
Exiele Daniel Fagundes de Oliveira $\mathbf{1}$ e Gabriela Ribeiro Peixoto Rezende Pinto $^{\mathbf{2}}$ \\ 1. Bolsista PROBIC/UEFS, Graduando em Engenharia de Computação, Universidade Estadual de Feira de Santana, \\ e-mail: ecomp.daniel@gmail.com \\ 2. Orientador, Departamento de Ciências Exatas, Universidade Estadual de Feira de Santana, e-mail: \\ gabrielarprp@gmail.com
}

PALAVRAS-CHAVE: Objetos de Aprendizagem; Ética em Computação; Website.

\section{INTRODUÇÃO}

Este trabalho é resultado do segundo ano de pesquisa do "OA TEC - Um Objeto de Aprendizagem para difundir os temas tratados no campo da Ética em Computação",que teve início em 2015, com o objetivo de projetar um espaço de aprendizagem para difundir temas da ética no âmbito da computação em formato de website (OLIVEIRA;PINTO, 2016).

O OA TEC, no entanto, era um website estático, onde para que novas informações, correções e modificações acontecessem, era necessário o programador modificar seu código interno. Para que modificações futuras acontecessem de forma dinâmica, sem necessidade de mudança no código, tornou-se necessário o planejamento e implantação de um sistema de gerência de banco de dados (SGBD), tanto quanto as modificações necessárias para a utilização do mesmo no website. Porém, devido aos problemas de hospedagem do site (não havia servidores disponíveis no Núcleo de Informática e Sociedade e não havia possibilidade de pagar por uma hospedagem na nuvem), e devido a segurança, e robustez oferecida pelo Google Sites, ficou decidido, como trabalho adicional, a recriação total do site utilizando a ferramenta do Google . Já que o Google disponibiliza seu próprio banco de dados para uso livre, não foi preciso implementar um SGBD/banco de dados próprio (G SUITE, 2017).

Adicionalmente também foi feita pesquisas bibliográficas para complementar o trabalho feito em 2015, trazendo livros publicados sobre ética em computação e e artigos publicados no Congresso Brasileiro de Educação em Engenharia (COBENGE). E, com isso, propor a difusão dos temas tratados por tal campo de conhecimento.

\section{MATERIAL E MÉTODOS OU METODOLOGIA (ou equivalente)}

Para a conquista do objetivo deste trabalho e para identificação dos dados relacionados à Ética em Computação, foi feita uma pesquisa bibliográfica utilizando as ferramentas de busca disponibilizadas gratuitamente pela empresa Google (Google Search e Google Books), também foi utilizada a biblioteca da Universidade Estadual de Feira de Santana (UEFS) para complementação e reforço dos resultados obtidos anteriormente. Para a pesquisa de artigos do COBENGE foi utilizado os anais disponibilizados pelo próprio COBENGE.

O site foi recriado na ferramenta de desenvolvimento Google Sites, que oferece hospedagem livre, e possui servidores robustos e confiáveis sem perigos de quedas ou superlotamentos. O Google Sites permite criar um site sem ter que saber como 
codificá-lo. Ele se enquadra na categoria Colaborativa no Google Apps for Work, o que significa que também se pode ter outros usuários do Google no processo de criação do site, o que o torna tão poderoso e uma ferramenta tão valiosa para equipes (G SUITE, 2017).

\section{RESULTADOS E/OU DISCUSSÃO (ou Análise e discussão dos resultados)}

$\mathrm{Na}$ pesquisa bibliográfica realizada em 2015, sobre os principais temas tratados no campo da Ética em Computação, foram encontrados quatro livros. Em 2016 essa pesquisa foi refeita englobando livros que não necessariamente abordassem temas específicos da ética em computação, mas que tocassem no assunto de algum tema relacionado, e não importando se estavam em português ou não. Assim, foram adicionados mais 10 livros à lista, são eles:

- CASTELLS, Manuel. A Sociedade em rede. A era da informação: economia, sociedade e cultura. Vol I. São Paulo: Paz e Terra ,1999.

- SILVEIRA, Amadeu da Silva. Software livre: a luta pela liberdade do conhecimento. São Paulo: Editora Fundação Perseu Abramo, 2004.

- HIMANEN, Pekka. A Ética dos hackers e o espírito da era da informação. Campus, 2001.

- JOHNSON, Debora G.; NISSENBAUM, Helen. Computers, Ethics \& Social Values. Prentice-Hall, 1995.

- KROKOSCZ, Marcelo. Autoria e plágio: um guia para estudantes, professores, pesquisadores e editores. São Paulo: Atlas, 2012.

- PIRES, F. E. O.; PIZZOLANTE, A. Habeas Data e Bancos de Dados: privacidade, personalidade e cidadania no Brasil Atual. Rio de Janeiro: Editora Lumen Juris, 2002.

- RECUERO, Raquel. Redes sociais na internet. Porto Alegre: Sulina, 2009.

- SANTOS, Antonio Jeová. Dano Moral na Internet. São Paulo: Método, 2001.

- SILVA, Amaro Moraes e. Privacidade na Internet: um enfoque jurídico. Bauru, SP: EDIPRO, 2001.

- SIlVEIRA, Amadeu da Silva. Exclusão digital: a miséria na era da informação. São Paulo: Editora Fundação Perseu Abramo, 2003.

Foi refeita também a pesquisa nos anais do Congresso Brasileiro de Educação em Engenharia (COBENGE), onde a busca foi feita minuciosamente pelo pesquisador verificando cada artigo em sua íntegra (antes feita automaticamente pelos títulos). Para abranger ainda mais o público alvo, foi feita a tradução completa e fiel dos códigos de ética da ACM e IEEE, e disponibilizados no site, onde também podem ser baixando em formato PDF. $O$ site criado abre espaço para difusão de conhecimento na área de ética em computação, e pode ser encontrado através do endereço https://sites.google.com/view/oatecweb. 
Todas as referências de todos os livros podem ser encontrados no site, na seção Referências e os artigos encontrados tanto em 2015 quanto em 2016 foram salvos e disponibilizados para download.

O site pode ser útil também em sala de aula. Professores podem utilizar deste acervo tanto para pesquisa quanto para demonstração dos objetos de aprendizagem para suas turmas, onde os alunos podem observar tanto com ajuda de um projetor, como por uso de celulares ou tablets. Observa-se que para o caso de apresentações em sala de aula, diversos fatores podem influenciar o total aproveitamento desta ferramenta, como disponibilidade de projetor/celulares/tablets, conexão de internet etc.

O novo site criado agora está com design completamente responsivo, cada página é agora uma única coluna de conteúdo fácil de ler que funciona bem seja em um desktop, tablet ou smartphone. A Figura 1 mostra a página do código de ética e conduta profissional da Association for Computing Machinery (ACM) aberta em um notebook e um celular, respectivamente. A Figura 2 mostra a página de seleção dos temas tratados na ética em computação (que também podem ser selecionados pelo menu) e a página sobre acesso não autorizado aberta, na seção de mídias e artigos.
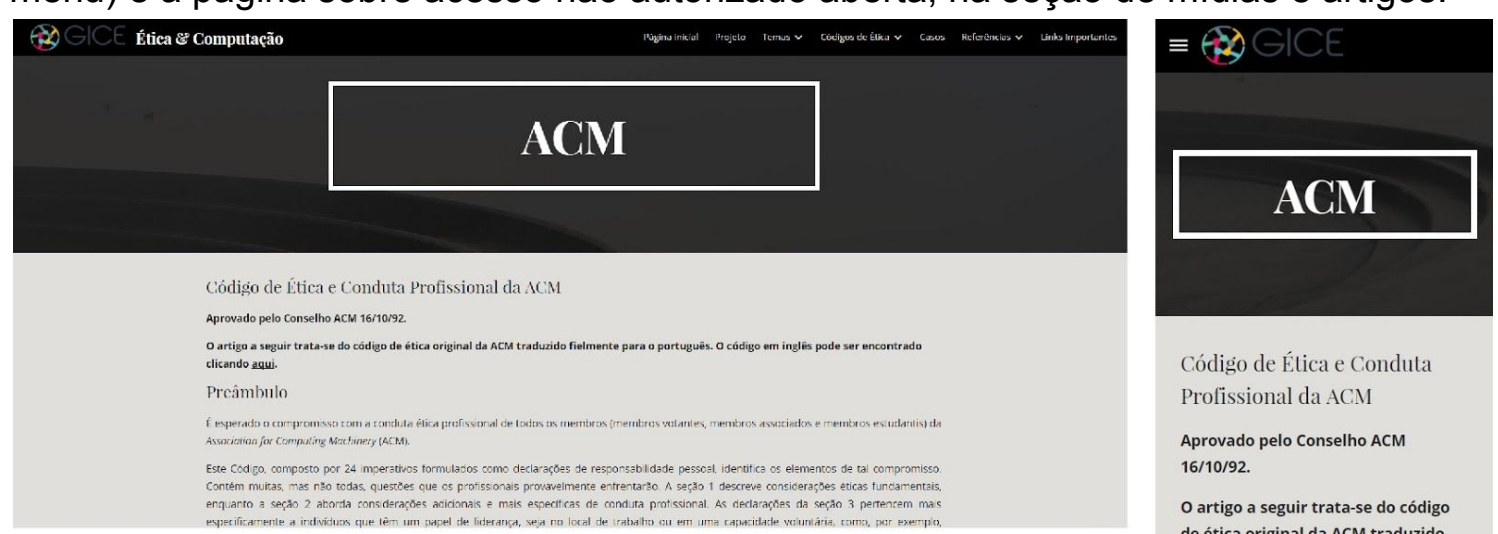

Código de Élica e Conduta Profissional da ACM

Aprovado pelo Conselho ACM $16 / 10 / 92$

O artigo a seguir trata-se do código de ética original da ACM traduzido fielmente para o português. $O$ código em inglês pode ser encontrado clicando aqui.

Figura 1 - comportamento do layout responsivo.

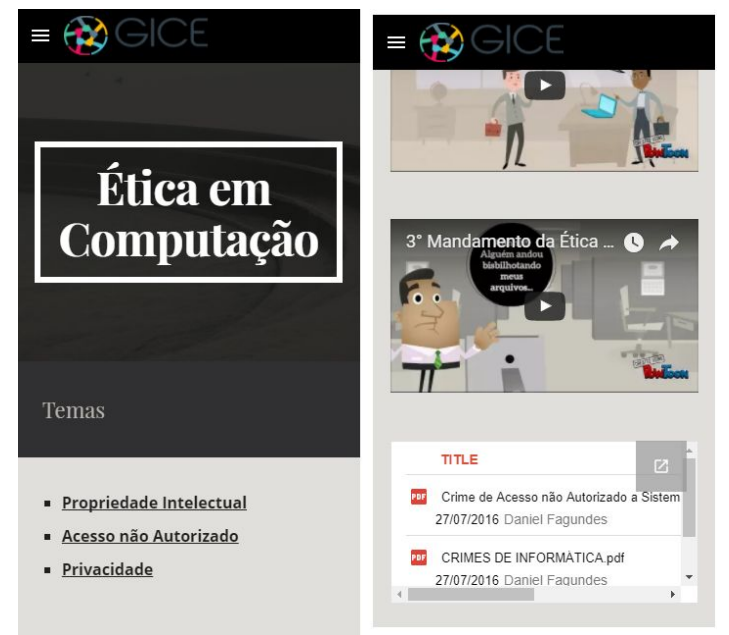

Figura 3-Temas da ética em computação 


\section{CONSIDERAÇÕES FINAIS (ou Conclusão)}

Com o intuito de contribuir para a difusão dos assuntos tratados no campo da ética em computação, bem como a promoção de debates críticos-reflexivos sobre eles, o site de ética em computação foi elaborado e implementado utilizando a ferramenta Google Sites. O site será uma importante fonte de conhecimento para a sociedade, dispondo de um acervo cuidadosamente acumulado de livros, artigos e mídias em geral sobre ética em computação. É importante, ainda assim, observar que os temas da ética em computação são pouco difundidos e abordados no Brasil, e o site criado é uma tentativa de reverter esse cenário. A equipe do GICE pretende dar continuidade aos trabalhos realizados com o site e mantê-lo sempre ativo e atrativo, visando sempre uma maior divulgação e abrangência desse espaço.

\section{REFERÊNCIAS}

G Suite, By Google Cloud. Disponível em:

$<$ https://gsuite.google.com.br/intl/pt-BR/products/sites/>. Acesso em 5 de agosto de 2017.

OLIVEIRA, E. D. F.; PINTO, G. R. P.R. Ética em Computação: Um campo de conhecimento a ser divulgado. In: XLIV CONGRESSO BRASILEIRO DE EDUCAÇÃO EM ENGENHARIA, 2016, Natal. Anais... Natal: CENTRO DE CONVENÇÕES - VIA COSTEIRA, 2016. 